Federal Reserve Bank of Minneapolis

Research Department Staff Report 275

August 2000

\title{
Societal Benefits of Nominal Bonds
}

\author{
Narayana R. Kocherlakota* \\ University of Minnesota \\ and Federal Reserve Bank of Minneapolis
}

\begin{abstract}
In this paper, I provide a possible explanation of why nominally risk-free bonds are essential in monetary economies. I argue that the role of nominal bonds is to serve as record-keeping devices in intertemporal exchanges of money. I show that bonds can only serve this role if they are illiquid (costly to exchange for goods). Finally, I show that in economies in which nominal bonds are essential, welfare and nominal interest rates are both positively associated with the supply of illiquid bonds (if that supply is small).

*Previous versions of this paper circulated under the title, "Optimal Co-existence of Money and Nominal Bonds." I thank Dean Corbae and Barbara McCutcheon for their comments. I also thank the participants in seminars at the Banco de Portugal, CEMFI, and the 2000 Conference on Advances in Monetary Theory and Payment Systems for their comments. The views expressed herein are those of the author and not necessarily those of the Federal Reserve Bank of Minneapolis or the Federal Reserve System.
\end{abstract}




\section{Introduction}

In many societies, individuals trade both money and nominal bonds. Often, as with Treasury bills, the bonds are essentially risk-free in nominal terms, and so they provide little benefit over money itself in terms of risk-sharing. Why then does a society find it beneficial to have both money and nominally risk-free bonds? To put the question in the jargon of monetary economics, What kinds of economic frictions lead to bonds and money both being essential?

In this paper, I provide an answer to this question. I show that in the equilibria of monetary economies, individuals may have different marginal rates of substitution between current and future consumption. Hence, individuals would like to engage in additional intertemporal trades of money. To make these intertemporal trades work, though, there must be a credible record of who received money in the past and who gave up money in the past.

I argue that the role of nominal bonds is to provide this credible record. More precisely, I show that if nominal bonds exist, some households can give up bonds for money, while others receive money for bonds. Later, the holders of the nominal bonds can exchange them for monetary interest rate payments. In this way, nominal bonds serve as a record-keeping device in the context of intertemporal monetary exchanges.

In making this argument, I find that it is important to distinguish between illiquid and liquid bonds. By illiquid, I mean bonds that cannot, because of physical or informational reasons, be exchanged for goods. I show that illiquid bonds can be used as a record-keeping device for intertemporal exchanges of money, but liquid bonds cannot be. In this sense, I endogenize the illiquidity of bonds by showing that it is efficient for bonds to be illiquid rather than liquid.

I formalize these arguments in a cash-in-advance model and a random-matching model in which agents experience unobservable shocks to their marginal utilities of consumption. I look at the consequences of adding three types of durable tokens - money, liquid bonds, and illiquid bonds - to these economies. I prove three results. The first is that, given the presence of money, liquid bonds are inessential: they can be eliminated with no loss in welfare. Intuitively, liquid bonds are equivalent to money, and there is never any reason to have both types of assets. 
The second result concerns the essentiality of illiquid bonds. I show that the unobservable taste shocks lead to illiquid bonds' being essential. In particular, agents with a high temporary need for consumption sell bonds and buy money; agents with a low temporary need for consumption do the opposite. As discussed above, illiquid bonds provide a way for agents with relatively low current consumption needs to credibly commit within an asset market to forgo consumption today in exchange for future consumption.

Finally, in environments in which illiquid bonds are essential, higher nominal interest rates are associated with higher welfare. The last result is contrary to the analyses of optimal monetary policy in representative agent cash-in-advance settings. There, zero nominal interest rates are optimal, and there is an inverse relationship between welfare and interest rates. The intuition behind my result is simple. If illiquid bonds are essential, then adding a small amount of illiquid bonds improves welfare. But with an increased supply of bonds relative to money, the price of bonds has to fall. Thus, in any economy in which nominal bonds are essential, we should expect small increases in the supply of bonds (when the supply is in the neighborhood of zero) to lead simultaneously to higher interest rates and higher welfare.

I derive these three results in two particular model environments. However, I argue that they are robust. The inessentiality of liquid bonds is an arbitrage argument and, as such, should be true in virtually any environment. Similarly, the positive association between welfare and interest rates when illiquid bonds are essential is a basic demand/supply story and, again, should be true in most environments. The essentiality of illiquid bonds is more delicate: it hinges on the agents' having different nominal intertemporal marginal rates of substitution and on these differences being difficult to observe.

It is important not to confuse the goal of this paper with that of a related stream of literature. There are many papers in monetary theory that ask the question, Why do individuals simultaneously hold money and bonds, even though bonds appear to generate the same flow of payments at a lower price? This question about individual behavior is fundamentally different from my question about societal behavior. My paper instead asks the question, Given a choice between bonds that are costly to use in goods transactions and bonds that are not, why do societies find it efficient to use the former? My paper endogenizes transaction costs: it shows why it is socially optimal for interest-bearing bonds to be costlier 
to use in goods markets than money is.

Throughout, I am agnostic about the source of this illiquidity. (I embed illiquidity in the model environments by assuming that bonds are not portable tokens.) There are many possible sources of this illiquidity. One is that the technology for detecting counterfeit bonds is available only in the asset market, not the goods market. Another is that to prevent theft, bond ownership may be costly to transfer to goods sellers. But I do not want to choose between these rationalizations: the goal of this paper is to show that illiquidity, whatever its source, has previously unappreciated societal benefits.

I also want to distinguish my paper from those that rationalize the co-existence of money and credit (among others, Corbae and Ritter (1999) and Townsend (1989)). In these papers, a barren token termed money is essential because it can be used as a record-keeping device for transactions among strangers. Simultaneously, though, it is not needed for recordkeeping within enduring relationships. In a similar vein, Kocherlakota and Wallace (1998) show that in worlds with imperfect centralized record-keeping systems, money can be essential because it helps fill the "holes" in the centralized record-keeping system. In contrast, my paper

provides a rationalization of why it is essential to have two different types of intrinsically useless tokens.

There is one other paper to my knowledge that addresses the societal benefits of having multiple nominally denominated assets. Aiyagari, Wallace, and Wright (1996) argue that if bonds and money are both indivisible, then their co-existence provides societal benefits through improving record-keeping. I think of my approach as being a useful complement to theirs: while indivisibility may well be an important factor in some situations, I doubt that it is the whole story in all settings. In particular, in modern economies, the indivisibility of money does not appear to be an important societal constraint.

\section{Islands Environment}

I begin by describing a simple islands economy. The environment is essentially that used by many authors to motivate a cash-in-advance monetary economy. 


\section{A. Physical Structure}

There is a unit measure of households in the environment. Each household has two members, a consumer and a producer. The households are characterized by a vector $(i, j) \in$ $\{1,2\} \times\{H, L\}$; there are equal measures of the four types of households.

There are two types of perishable goods in this setting. The first component of this vector describes the types of goods produced and consumed by the household: type 1(2) households produce type 1(2) goods and consume type 2(1) goods. The latter two components are preference parameters. Specifically, a type $(1, j)$ household has preferences representable by

$$
\theta_{j} \ln \left(c_{1}\right)-\alpha y_{1}+\sum_{t=2}^{\infty} \beta^{t-1}\left\{\ln \left(c_{t}\right)-\alpha y_{t}\right\}
$$

where $c_{t}$ is consumption of type 2 goods and $y_{t}$ is production of type 1 goods. I assume that $0 \leq y_{t} \leq 1, \theta_{H}>1>\beta$, and $\theta_{L}=1$. Type $(2, j)$ households have similar preferences with the obvious changes in goods produced and consumed.

There are three islands in the world labeled 1,2, and 3. At the beginning of each period, all households are located on island 3 together. This island has no endowment of goods or means of production. Then the type 2(1) producers go to island 2(1), and the type $1(2)$ consumers go to island 2(1). On these islands, production and consumption take place. All goods are perishable.

I make the following three assumptions about enforcement and information. The first two are standard ways to generate a role for money: I assume that there is no record-keeping technology (other than the durable tokens that I describe later), and I assume that society cannot impose any penalties on households. This means, among other things, that type 2 producers cannot be required to produce for type 1 consumers, because there is no way to force them to do so. Finally, I assume that for a type $(i, j)$ household, $i$ is publicly observable, but $j$ is not.

\section{B. Tokens}

I investigate economies that are distinguished by the types of tokens that are available. All of the economies have a durable and divisible token called money. Money can be costlessly created by society (but individual households cannot do so). 
The economies differ, though, in the availability of bonds. A bond is a token which physically lasts for only one period: it physically disappears after the period 2 meeting of all households on island 3. All of the bonds are nominal: immediately before a unit of bonds completely depreciates, the holder can exchange it for a unit of newly created money.

There are two types of bonds: liquid and illiquid. A liquid bond is a bond which can be traded on all islands at all dates. An illiquid bond can be traded only on island 3 . These differences in bond types can be physically interpreted as saying that bonds are either portable or not.

In what follows, I measure holdings of bonds in terms of their nominal payoff at time of maturity. Thus, $B$ units of one-period bonds refers to the payoff of $B$ units of money that the holder receives in period 2. In a no-bond economy, all households begin life with $M$ units of money. In a liquid-bond economy, all households begin life with $M$ units of money and $B$ units of liquid bonds. Finally, in an illiquid-bond economy, all households begin life with $M$ units of money and $B$ units of one-period illiquid bonds.

The rules of exchange in all economies are the same. On island 3, agents trade money, liquid bonds, and illiquid bonds in a competitive market. I denote the relative price of bonds in terms of money in this market by $q$. On islands 1 and 2 , the agents located on those islands trade money, liquid bonds, and goods in a competitive market. I denote the period $t$ relative price of goods in terms of money in this market by $p_{t}$. Thus, all of the economies are essentially cash-in-advance economies, where cash includes both money and liquid bonds.

\section{Results in the Islands Environment}

In this section, I describe and prove the three main results in the paper. Note first, though, that because of the enforcement and record-keeping limitations, money itself is essential in all economies.

\section{A. Inessentiality of Liquid Bonds}

The first result is that any equilibrium allocation in the liquid-bond economy is an equilibrium allocation in the no-bond economy. This is easily demonstrated through arbitrage. In the liquid-bond economy, to avoid arbitrage opportunities, the relative price of money and bonds must be one in both goods and asset markets in periods 1 and 2. Suppose this were 
not so. In the period 1 goods market on either island 1 or island 2 , there is a positive supply of bonds and money. If the relative price of bonds in terms of money is less (more) than one, then all households will hold only bonds (money). Hence, the relative price must be one. But this kind of argument can be unraveled backwards to prove that the relative prices must always be one. Given that this is true, we can replace all bonds with an equivalent amount of money, and the liquid-bond equilibrium will then be a no-bond equilibrium.

The intuition behind this argument is clear. If bonds are as liquid as money, then people will only hold money if nominal interest rates are zero. But then the bonds can just be replaced by money: there is no difference between the two instruments at all.

Despite (because of?) its simplicity, the implications of the result are strong: adding nominal bonds to a monetary economy only improves welfare if those bonds are at least somewhat less liquid than money. Any essentiality of nominal bonds can be traced directly to their (relative) illiquidity.

\section{B. Essentiality of Illiquid Bonds}

The second main result concerns the essentiality of illiquid bonds. I construct equilibria in the no-bond economy and the illiquid-bond economy. I demonstrate that welfare is higher in the latter equilibrium. Throughout, I assume that $\beta>\alpha$. As we shall see, this assumption serves to eliminate the inflationary distortion on household labor supply, which makes welfare comparisons more straightforward.

\section{No-Bond Economy}

In the no-bond economy, if $\left\{p_{t}\right\}_{t=1}^{\infty}$ is the sequence of price levels, a type $(i, j)$ household faces the following decision problem:

$$
\begin{aligned}
& \max _{\left\{c_{j t}, n_{j t}, M_{j t}\right\}_{t=1}^{\infty}} \theta_{j} \ln \left(c_{j 1}\right)-\alpha y_{j 1}+\sum_{t=2}^{\infty} \beta^{t-1}\left\{\ln \left(c_{j t}\right)-\alpha y_{j t}\right\} \\
& \text { s.t. } p_{t} c_{j t} \leq M_{j, t-1} \\
& p_{t} c_{j t}+M_{j t} \leq M_{j, t-1}+p_{t} y_{j t} \\
& M_{j t}, c_{j t} \geq 0 \\
& 0 \leq y_{j t} \leq 1
\end{aligned}
$$




$$
M_{j 0}=M .
$$

Here, $c_{j t}$ is consumption in period $t, y_{j t}$ is production in period $t$, and $M_{j t}$ is money holdings in period $t$. Because of the spatial separation in the environment, consumers in household $j$ have to use previously accumulated money balances to buy goods in period $t$. This "cash-inadvance" restriction is embedded in the set of constraints in the household's problem.

It is then straightforward to show that the following is an equilibrium:

$$
\begin{aligned}
p_{t} & =M \text { for all } t \\
c_{j t} & =1 \text { for all } t, j \\
y_{j t} & =1 \text { for all } t, j .
\end{aligned}
$$

(My choice of numeraire rules out the equilibrium in which money is not valued at all. If consumption goods were the numeraire, such an equilibrium would exist, and autarky would be the equilibrium allocation.) In the Appendix, I prove that this is the unique equilibrium for any $\theta_{H}$.

Because they are liquidity-constrained, both types of households consume the same amount of consumption in period 1. Note that this is not consistent with a first-best Pareto optimum, in which $\theta_{H}$ households would consume more in period 1 than the other households.

The unobservability of the household's taste shocks plays an important role here. If taste shocks were observable, the social planner could create new money and hand it to the $\theta_{H}$ households before trading begins. In this way, households could be insured against their taste shocks.

\section{Illiquid-Bond Economy}

In the illiquid-bond economy, if $q$ is the relative price between bonds and money in period 1 and $\left\{p_{t}\right\}_{t=1}^{\infty}$ is the sequence of price levels, type $(i, j)$ households face the following decision problem:

$$
\begin{aligned}
& \max _{\substack{\left\{c_{j t}, n_{j}, M_{j t}\right\} \\
M_{j 0}^{\prime}, B_{j 1}}} \theta_{j} \ln \left(c_{j 1}\right)-\alpha y_{j 1}+\sum_{t=2}^{\infty} \beta^{t-1}\left\{\ln \left(c_{j t}\right)-\alpha y_{j t}\right\} \\
& \text { s.t. } M_{j 0}^{\prime}+q B_{j 1} \leq M+q B
\end{aligned}
$$




$$
\begin{aligned}
& p_{1} c_{j 1} \leq M_{j 0}^{\prime} \\
& M_{j 1} \leq M_{j 0}^{\prime}-p_{1} c_{j 1}+p_{1} y_{j 1}+B_{j 1} \\
& p_{t} c_{j t} \leq M_{j, t-1}, t \geq 2 \\
& M_{j t} \leq M_{j, t-1}-p_{t} c_{j t}+p_{t} y_{j t}, t \geq 2 \\
& M_{j t}, c_{j t}, y_{j t}, M_{j 0}^{\prime}, B_{j 1} \geq 0 \\
& 0 \leq y_{j t} \leq 1 .
\end{aligned}
$$

This decision problem represents the sequence of markets that households face. In period 1 , households can trade money and bonds at price $q$. Then consumers take the available money (bonds are illiquid) and buy goods. In period 2, households can use the money balances and the payments from bonds to buy goods. From period 3 on, the decision problem is the same as in the no-bond economy.

Given this decision problem, it is straightforward to show that the following is an equilibrium for sufficiently small $B$ :

$$
\begin{aligned}
y_{j t} & =1 \text { for all } j, t \\
q & =\beta M /(M+\beta B+2 B) \\
p_{1} & =M \\
p_{t} & =(M+B), t>1 \\
c_{h 1} & =(M+B q) / M \\
c_{l 1} & =(M-B q) / M \\
c_{h 2} & =M /(M+B) \\
c_{l 2} & =(M+2 B) /(M+B) \\
c_{j 2} & =1, t>2 .
\end{aligned}
$$

Let me explain how this equilibrium works. In period 1, on island 3, type $H$ agents sell all of their illiquid bonds at price $q$ to the type $L$ agents. Because they have more cash, the type $H$ agents can consume more in period 1 than type $L$ households (note that the type $L$ households end up carrying both bonds and money into period 2). All households work 
the full amount possible, because they are at a corner; hence, they all carry the same amount of money into the next period.

In period 2 , on island 3 , the type $L$ agents receive the payoff from their illiquid bonds. Hence, they can consume more in period 2 than the type $H$ agents. Again, in period 2, all agents work the same amount. This ensures that in all future periods, all agents consume the same amount.

It is straightforward to show that all agents are made better off in this equilibrium than in the no-bond equilibrium allocation. In particular, it is budget-feasible for the agents to spend $M$ in period 1 and then spend $(M+B)$ in period 2. This means that the no-bond equilibrium allocation is budget-feasible in the illiquid-bond economy, but agents strictly prefer not to choose it.

Thus, in this model environment, all agents are made better off by the introduction of illiquid bonds. Both illiquid bonds and money are essential. ${ }^{1}$

\section{But What About the Friedman Rule?}

In representative-agent versions of cash-in-advance economies, it is well-known that if the money supply shrinks at the rate of time preference (or at any rate at all, for that matter), there is a Pareto optimal equilibrium allocation. (See Cole and Kocherlakota (1998) for example.) This result carries over to the above heterogeneous agent economy as well: if the money supply falls to zero asymptotically in the no-bond economy, there exists an equilibrium in which the associated allocation is Pareto optimal. There is then no need for illiquid bonds in the economy.

However, in the islands environment discussed in this paper, society cannot impose any penalties on households. If such penalties could be imposed, then there is no role for money, because producers could just be forced to produce for households. Without this ability to impose penalties, it is not possible to shrink the money supply because there is no way to force individuals to give up their money.

While logically correct, this argument may not strike all readers as compelling. For

\footnotetext{
${ }^{1}$ Note that agents would be even better off if they were allowed to trade one-period illiquid bonds on island 3 every period, not just in period 1.
} 
those readers, let me simply say that the above demonstration of the essentiality of illiquid bonds does rely on the money supply being bounded from below. This bound could be present because of some enforcement friction (as in this environment) or some technological limitation that prevents money from being divided too finely.

In Levine (1991), the socially optimal allocation of resources is an equilibrium if the money supply grows sufficiently fast. It is important to check if this result is true in this environment. If it were, then there would be no role for bonds, because the government could (at least weakly) implement the efficient allocation by simply injecting money into the economy each period.

In the Appendix, I allow for the possibility that in the no-bond economy, the government injects additional money into the economy at the beginning of every period via equal transfers for all households. I show that for any weakly increasing sequence of money supplies $\left\{M_{t}\right\}_{t=1}^{\infty}$ and any $\theta_{H}$, the equilibrium allocation of resources is given by

$$
c_{j t}=y_{j t}=\min \left(\alpha^{-1} \beta M_{t} / M_{t+1}, 1\right) \text { for all } t \text { and } j=H, L
$$

which provides less utility to all households than the equilibrium in the illiquid-bond economy described above. Intuitively, even though the low-shock households are more patient than the high-shock households, the low-shock households are still impatient (in the sense that at their endowments, their shadow real interest rates are positive). It is therefore not possible to separate the two types by using inflationary policy as in Levine (1991).

\section{Welfare Benefits of High Nominal Interest Rates}

Now consider increasing the supply $B$ of bonds in the above illiquid-bond economy. If $B$ increases slightly, then, since

$$
q=\beta M /((2+\beta) B+M)
$$

$q$ falls as $B$ rises. Moreover, household welfare is increasing in $B$ (at least) for small values of $B$. It follows that as $M / B$ varies, interest rates and household welfare move in the same direction. 


\section{Random-Matching Environment}

I now show how these same results apply in a simple random-matching setup (similar to that described in Kiyotaki and Wright (1991)).

\section{A. Physical Structure}

Consider an economy with a unit measure of infinitely lived agents. There are equal measures of three types of agents and, correspondingly, three types of indivisible, nondurable goods. In any given period, type $i$ agents can produce one unit of type $i$ goods at utility cost $0<c<1$.

In all periods but the first, type $i$ agents receive utility benefit 1 from consuming one unit of type $(i+1)$ goods. In the first period, a randomly determined half of the type 1 agents receive utility benefit $\theta_{H}>1$ from consuming one unit of type 2 goods. All other agents receive utility benefit 1 from consuming one unit of type $(i+1)$ goods. All agents have a common discount factor $\beta$, where $0<\beta<1$.

The physical structure of the environment is as follows. There are three islands. At the beginning of each period, all type $i$ agents are on island $i$. Within the period, agents are matched randomly into pairs. The pairs are informationally and physically separated.

As before, there is no record-keeping technology (beyond the tokens described below) and no enforcement technology. As well, the utility benefit of period 1 consumption is private information.

\section{B. Tokens and Trade}

As before, I study versions of the above economy that are distinguished by the nature of the available tokens. All of the economies have a durable and, as is common in the random-matching literature, indivisible token called money. Money can be costlessly created by society (but individual households cannot do so).

The economies differ, though, in the availability of bonds. A bond is a token which physically lasts for only one period: it physically disappears after the period 2 meetings of type $i$ households on island $i$. All of the bonds are nominal: immediately before a unit of bonds completely depreciates, the holder can exchange it for a unit of newly created money.

There are two types of bonds: liquid and illiquid. Here, a liquid bond is a bond which 
can be exchanged for money on any island at the beginning of period 2 . In contrast, an illiquid bond can be exchanged for money only on island 1 at the beginning of period 2 (so type 2 agents are not willing to accept illiquid bonds in exchange for goods).

I study three different types of economies distinguished by the types of tokens available for trade. In what follows, I measure holdings of bonds in terms of their nominal payoff at time of maturity. Thus, $b$ units of one-period bonds refers to the payoff of $b$ units of money that the holder receives in period 2. In a no-bond economy, a fraction $m$ of households begin life with one unit of money. In a liquid-bond economy, a fraction $m$ of households begin life with one unit of money and a fraction $b$ of type 1 households begin life with one unit of liquid bonds. Finally, in an illiquid-bond economy, a fraction $m$ of households begin life with one unit of money and a fraction $b$ of type 1 households begin life with one unit of illiquid bonds. In the bond economies, no households are initially endowed with both money and bonds.

As is standard in random-matching environments, I impose an upper bound on portfolios. No household can hold more than one unit of money or one unit of bonds. However, a household can simultaneously hold a unit of money and a unit of bonds.

I model trading in the pairwise matches in a rather standard way: type $i$ agents make take-it-or-leave-it offers to type $(i+1)$ agents. (The results that I stress are robust to perturbing this trading mechanism.) I refer to matches as being tradeable matches if they involve a type $i$ agent with a unit of money (and/or a unit of liquid bonds) and a type $(i+1)$ agent with neither money nor liquid bonds.

Bond/money trading on island 1 is more difficult to model. Because all of the agents are physically together, it makes sense to think of their trading in a large market, rather than in pairwise matches. However, as we will see, agents with money will only be willing to exchange it for a bond if the money is somehow worth more than the bond. This is difficult to model, given the indivisibility of the two tokens.

To deal with this issue, I adopt the following notion of trade on island 1 . Trade is competitive, with the market-clearing price being a probability of exchange of money and bonds. Hence, given a bond price $q$, an agent with money who agrees to trade receives a bond with probability one and loses a unit of money with probability $q$. Similarly, given a bond price $q$, an agent with a bond who agrees to trade loses that bond with probability one 
and receives a unit of money with probability $q$. A price $q$ is an equilibrium if the measure of bondholders who agree to trade is equal to the measure of moneyholders who agree to trade.

\section{Results in the Random-Matching Environment}

In this section, I describe how the three main results work in this environment.

\section{A. Inessentiality of Liquid Bonds}

It is straightforward to show that liquid bonds are inessential: Any equilibrium outcome in the liquid-bond economy is an equilibrium outcome in the purely monetary economy.

To see this, note first that in the period 1 matches, sellers of goods view money, liquid bonds, or a combination thereof as being equivalent. This immediately implies that the value of holding money or liquid bonds is the same at the beginning of period 1 . Hence, in the period 1 money/bond trading on island 1, if $q<1$, no bondholder will agree to trade, and all moneyholders will. It follows that in equilibrium, $q=1$, and this equilibrium can be exactly mimicked by replacing the liquid bonds with money.

\section{B. Essentiality of Illiquid Bonds}

Consider a no-bond economy. Suppose that a fraction $m$ of the agents are endowed with money, and suppose that $c$ is sufficiently small so that it is an equilibrium for money and goods to always be exchanged in tradeable matches. In other words, suppose that

$$
-c+\beta\left(V_{m}-V_{0}\right)>0
$$

where

$$
\begin{aligned}
V_{m} & =(1-m)\left[1+\beta V_{0}\right] / 3+(1-(1-m) / 3) \beta V_{m} \\
V_{0} & =m\left[-c+\beta V_{m}\right] / 3+(1-m / 3) \beta V_{0} .
\end{aligned}
$$

It is easy to show using simple algebra that

$$
\begin{aligned}
V_{\text {nobond }}^{*}= & m(1-m)\left(\theta_{H}-c\right) / 18+5 m(1-m)(1-c) / 18 \\
& +\beta[m(1-m)(1-c) / 3](1-\beta)^{-1}
\end{aligned}
$$

is the average utility of agents in this equilibrium in the no-bond economy. 
At this point, construct an illiquid bond economy by initially endowing a fraction $b$, where $m>b>0$, of type 1 agents with illiquid bonds in such a way that no agent has more than one asset. In this economy, I describe a particular pattern of trades and argue that if $\theta_{H}$ is sufficiently high and $b$ is sufficiently low, this pattern of trades is an equilibrium.

The pattern of exchanges has the following form. In the initial bond/money market, all of the high-shock type 1 agents with bonds give up their bonds in exchange for money and a measure $b / 6$ of the low-shock type 1 agents with money give up their money in exchange for bonds, at some price $q$ in $(0,1)$. After this market closes, money and goods are exchanged in all tradeable matches.

Now suppose that agents are following this pattern of exchanges. We can then define $\Delta_{i t}(b, q)$ to be the period $t$ utility benefit to type $i$ agents having money (as opposed to not having money), given an initial bond supply $b$ and a period 1 bond price $q$. It is straightforward to show that $\Delta_{i t}(b, q)$ is continuous in $(b, q)$. As well, $\Delta_{i t}(b, q)$ is uniformly bounded from below by zero, and so

$$
\Delta^{*}(b) \equiv i n f_{t, i, q} \Delta_{i t}(b, q)=\min _{t, i, q} \Delta_{i t}(b, q)
$$

It follows from the Theorem of the Maximum that $\Delta^{*}(b)$ is continuous in $b$. Since $\Delta^{*}(0)>c \beta^{-1}$ (because $\Delta_{i t}(0, q)=V_{m}-V_{0}>c \beta^{-1}$ for all $\left.i, t, q\right)$, it follows that there exists $b^{*}$ such that $\Delta^{*}(b)>c \beta^{-1}$ for all $0<b<b^{*}$. Thus, as long as $b<b^{*}$, it is an equilibrium for agents to always trade goods for money in tradeable matches, regardless of the value of $q$.

Suppose, then, that $b^{*}>b>0$. We must now determine the equilibrium price $q$ in the period 1 bond/money market. Because $b<m$, bonds are scarce, and so it must be true in equilibrium that the high-shock bondholders weakly prefer to give up their bonds and the low-shock moneyholders are indifferent between trading and not trading. The former condition is easily satisfied by making $\theta_{H}$ sufficiently large.

The indifference condition for the low-shock moneyholders is more difficult. When they give up their money, the moneyholders lose the ability to consume in period 1 (because bonds are illiquid). However, they only give up their money with probability $q$. With probability $(1-q)$, they keep their money and receive in addition an illiquid bond. This additional illiquid bond gives them the ability to consume in period 1 without losing any future utility. 
In other words, to have indifference, it must be true that

$$
-q+(1-q) \Delta_{12}(q, b)=0 .
$$

(Recall that $\Delta_{12}(q, b)$ is the utility difference for a type 1 agent between having money in period 2 and not having money in period 2.) Clearly, from the Intermediate Value Theorem, there exists some $q$ that satisfies this equation (simply check the value of the left-hand side of the equation for $q=1$ and $q=0$ ), and so there is an equilibrium of the required kind in the money/bond market.

To sum up, we have constructed an equilibrium in which more high-shock type 1 agents receive a consumption good in period 1 than in the no-bond economy. This represents a welfare benefit. There are three other (potential) welfare losses associated with this new equilibrium. First, fewer low-shock type 1 agents consume in period 1. Second, some type 3 agents receive less consumption in period 1 (because type 1 agents with bonds do not want to produce). Finally, the distribution of money across types is now unequal at the beginning of period 2. All of these potential losses are finite and are unaffected by changing $\theta_{H}$. Hence, by making $\theta_{H}$ arbitrarily high, this equilibrium in the illiquid-bond economy will dominate the equilibrium in the no-bond economy. In other words, illiquid bonds are essential as long as $\theta_{H}$ is sufficiently large.

This last argument should make clear why I assume that the preference shock impinges only on type 1 agents. Type 1 agents with bonds do not produce in period 1 . Hence, if some type 3 agents are hit by the preference shock, their welfare loss is proportional to $\theta_{H}$. It is then no longer clear that bonds improve welfare for sufficiently high values of $\theta_{H}$.

\section{Welfare Benefits of Higher Interest Rates}

The final result in this economy is that higher nominal interest rates may be associated with higher amounts of welfare. To see this, note first that $\Delta_{12}(q, b)$ is a weakly decreasing function of both $q$ and $b$ (increasing $q$ and $b$ increases the amount of money in period 2 and therefore decreases the value of money in that period).

Now, increase $b$ slightly. Since adding bonds improves welfare in the above economy, we know that welfare is increasing in $b$ for small values of $b$. As well, $\Delta_{12}(q, b)$ declines. It follows that to satisfy the indifference requirement for low-shock moneyholders, it must be 
true that $q$ declines. Thus, welfare goes up along with an increase in nominal interest rates.

\section{Intuition and Robustness}

In this section, I first argue that there is a strong intuition underlying the three main results. Hence, even though they are derived in special settings, I conjecture that they are true in a large class of environments.

\section{Inessentiality of Liquid Bonds: Intuition}

The first result is that liquid bonds are inessential. The intuition behind this result is that if bonds are liquid, then their price must always be the same as money, or bond/money markets cannot clear. Hence, money and bonds are exactly equivalent instruments - there is no need to distinguish between the two. This arbitrage-based result seems likely to be highly robust.

\section{Essentiality of Illiquid Bonds: Intuition}

The second result is that illiquid bonds are essential. This result is more delicate, because it depends on three frictions. The first is that record-keeping must be limited. Otherwise, whatever the bonds are doing could be done using a record-keeping technology. Of course, as Kocherlakota (1998) emphasizes, without record-keeping limitations of some kind, money itself is inessential.

At least in the islands economy, it is also important that enforcement be limited. If there are no enforcement frictions, then by shrinking the money supply, the planner can (at least weakly) implement a first-best allocation of resources. Again, though, we know from Kocherlakota (1998) and Huggett and Krasa (1996) that without some enforcement frictions, money itself is inessential.

Finally, there must be some unobservable differences in the households' intertemporal nominal marginal rates of substitution in the purely monetary economy. The households would like to eliminate this difference, but because of the above enforcement/record-keeping limitations, they can only do so by using bonds as a record-keeping device.

There is a counterintuitive element to the essentiality of illiquid bonds: Why are households better off using a less flexible asset? The reason is simple. Households wish to 
engage in an intertemporal exchange of consumption. Because of spatial separation, they can engage in these trades only in the asset market. So, in the asset market, a low-shock household must guarantee that it is giving up first-period consumption in exchange for more second period consumption. The only way that they can do so is by buying bonds that are not as liquid as money.

Again, the intuition behind this result seems fairly robust. In particular, I conjecture that it will survive other ways of introducing differences in liquidity demands across model entities. (For example, the result should be true in a setting with firms that need money to hire inputs into production and that differ in terms of productivity shocks.)

\section{Welfare Benefits of Higher Nominal Interest Rates: Intuition}

In the illiquid-bond economy, larger bond supplies are associated with higher period 1 nominal interest rates and with higher levels of household welfare. Again, there is a simple (and robust) intuition behind this result. In an economy in which illiquid bonds are essential, adding a small amount of illiquid bonds makes agents better off (by definition). But increasing the supply of bonds will typically drive their price downward and increase the nominal interest

rate. Hence, if illiquid bonds are essential, then higher nominal interest rates should be expected to be associated with higher levels of welfare.

\section{Conclusions}

The purpose of this paper is to provide a rationalization of the co-existence of illiquid bonds and money. The key ingredients in this rationalization are twofold. First, enforcement is limited, and record-keeping is impossible except through durable tokens. Second, households are affected by taste shocks that lead to differences in their willingness to substitute money over time. These taste shocks are impossible to observe. Together, these frictions give rise to a need for an auxiliary, illiquid record-keeping device.

The paper also shows that in economies in which illiquid bonds are essential, standard welfare analyses of monetary policy must be revised. In particular, when bonds are essential, increasing the supply of bonds leads to a simultaneous decrease in their price and increase in consumer welfare. Thus, welfare and interest rates end up being positively associated.

This paper represents a first step toward understanding the societal benefits of having 
assets that differ in their liquidity properties. It would be useful to extend the analysis to account for finer gradations of liquidity. I plan to address this question in future work. 


\section{Appendix}

In this appendix, I consider an extended version of the no-bond islands economy presented in the text. I allow for the possibility that at the beginning of every period, households receive equal non-negative transfers of new money. I show that for any weakly increasing sequence of money supplies, there is a unique monetary equilibrium in the no-bond islands economy.

The proof works as follows. I first show that there is a unique equilibrium in the case in which $\theta_{H}=1$. I then build on this lemma to prove that there is a unique equilibrium for all $\theta_{H}$.

LEMmA 1. Let $\left\{M_{t}\right\}_{t=0}^{\infty}$ be a weakly increasing sequence of money supplies. If $\theta_{H}=1$, there is a unique equilibrium in which $p_{t}=M_{t}, c_{j t}=1$, and $y_{j t}=1$ for all $t$.

Proof. It is straightforward to show that any equilibrium must be symmetric in that all households have the same consumption-labor choices.

The first part of the proof is that in equilibrium, if the multiplier on the household's cash-in-advance constraint is zero in any period $t$, then it must be zero in all future periods. Let $\lambda_{t}$ be the multiplier on the household's period $t$ flow wealth constraint, and $\mu_{t}$ be the multiplier on its period $t$ cash-in-advance constraint. Suppose that $\mu_{\tau}=0$ for $s>\tau \geq t$ and $\mu_{s}>0$. Then

$$
\beta^{t} /\left(p_{t} c_{t}\right)=\lambda_{t}=\lambda_{s}+\mu_{s}=\beta^{s} /\left(p_{s} c_{s}\right)=\beta^{s} / M_{s}
$$

which implies that

$$
1<\beta^{t-s}=p_{t} c_{t} / M_{s} \leq M_{t} / M_{s}
$$

which contradicts the specification that the money supply is weakly increasing.

The second part of the proof is that if $\mu_{t}=0$ for all $t \geq T$, then the household's transversality condition is violated, because

$\lim _{s \rightarrow \infty} \beta^{s} /\left\{p_{s} c_{s}\right\}=\beta^{T} /\left(p_{T} c_{T}\right)>0$.

The first two parts of the proof combine to tell us that $\mu_{t}>0$ for all $t$. It follows that $p_{t} c_{t}=M_{t}$ 
for all $t$, and so all households consume the same amount in every period. Moreover, the households' labor supply first-order condition looks like

$$
\begin{aligned}
& -\alpha+\beta p_{t} /\left(p_{t+1} c_{t+1}\right) \\
= & -\alpha+\beta M_{t} /\left(M_{t+1} c_{t}\right) .
\end{aligned}
$$

If $\alpha \leq \beta M_{t} /\left(M_{t+1}\right)$, then $c_{t}=1$. If $\alpha>\beta M_{t} / M_{t+1}$, then $c_{t}=\alpha^{-1} \beta M_{t} / M_{t+1}$. Hence, in equilibrium, $y_{t}=\min \left(\alpha^{-1} \beta M_{t} / M_{t+1}, 1\right)$ for all $t$.

The lemma (and its proof) can be used to prove the proposition that for any $\theta_{H}$, there is a unique monetary equilibrium, and in that equilibrium, the cash-in-advance constraint always binds.

Proposition 1. Let $\left\{M_{t}\right\}_{t=0}^{\infty}$ be a weakly increasing sequence of money supplies. Then, for all $\theta_{H}$, there is a unique equilibrium in which for all $j, t$

$$
\begin{aligned}
p_{t} & =M_{t} \\
c_{j t} & =y_{j t}=\min \left(\alpha^{-1} \beta M_{t} / M_{t+1}, 1\right) .
\end{aligned}
$$

Proof. Consider first an equilibrium in which, in period 1, the cash-in-advance constraint binds type $L$ households. Then the type $L$ household's solution to its choice problem satisfies the first order conditions of the type $H$ household's problem and therefore also solves the type $H$ household's problem. It follows that the cash-in-advance constraint binds type $H$ households in period 1. From Lemma 1, we know that in any such equilibrium, the cash-inadvance constraint binds both types of households in all periods (because they begin period 2 with equal amounts of money). Hence, we know that the only equilibrium in which the cash-in-advance constraint binds type $L$ households in period 1 has $p_{t}=M_{t}$ and $c_{j t}=y_{j t}=1$.

Now I prove that there is no equilibrium in which the cash-in-advance constraint fails to bind type $L$ households in period 1 . Consider such an equilibrium. From the logic in the proof of Lemma 1, the cash-in-advance constraint must eventually bind type $L$ households (or their transversality conditions are not satisfied). Suppose that the cash-in-advance constraint 
binds first in period $s$. Then, again using logic from the proof of Lemma 1, we know that

$$
1 /\left(p_{1} c_{L 1}\right)=\lambda_{L 1}=\lambda_{L s}+\mu_{L s}=\beta^{s-1} /\left(p_{s} c_{L s}\right)=\beta^{s-1} / M_{L s} .
$$

Moreover, because of the preference shock, type $L$ households spend no more in period 1 than type $H$ households, and therefore $M_{H s} \leq M_{L s}$. It follows that $M_{L s}>M_{0}$. But this implies that $M_{0}<p_{1} c_{L 1}$, which violates the cash-in-advance constraint. It follows that there is no such equilibrium. 


\section{References}

[1] Aiyagari, S. R., Wallace, N., and Wright, R., 1996, Coexistence of money and interestbearing securities, Journal of Monetary Economics 37, 397-420.

[2] Cole, H., and Kocherlakota, N., 1998, Efficient allocations with hidden income and hidden storage, Research Department Staff Report 238, Federal Reserve Bank of Minneapolis.

[3] Corbae, D., and Ritter, J., 1999, Money and search with enduring relationships, University of Pittsburgh working paper.

[4] Huggett, M. and Krasa, S., 1996, Money and storage in a differential information economy, Economic Theory 8, 191-210.

[5] Kiyotaki, N. and Wright, R., 1991, A contribution to the pure theory of money, Journal of Economic Theory 53, 215-35.

[6] Kocherlakota, N. R., 1998, Money is memory, Journal of Economic Theory 81, 232-51.

[7] Kocherlakota, N. R., and Wallace, N., 1998, Incomplete record-keeping and optimal payment arrangements, Journal of Economic Theory 81, 272-89.

[8] Levine, D. K., 1991, Asset trading mechanisms and inflationary policy, Journal of Economic Theory 54, 148-64.

[9] Townsend, R., 1989, Currency and credit in a private-information economy, Journal of Political Economy 97, 1323-44. 